\title{
References
}

1 Nixon GM, Armstrong DS, Carzino R, et al. Clinical outcome after early Pseudomonas aeruginosa infection in cystic fibrosis. J Pediatr 2001; 138: 699-704.

2 Emerson J, Rosenfeld M, McNamara S, et al. Pseudomonas aeruginosa and other predictors of mortality and morbidity in young children with cystic fibrosis. Pediatr Pulmonol 2002; 34: 91-100.

3 Frederiksen B, Koch C, Hoiby N. Antibiotic treatment of initial colonization with Pseudomonas aeruginosa postpones chronic infection and prevents deterioration of pulmonary function in cystic fibrosis. Pediatr Pulmonol 1997; 23: 330-335.

$4 \quad$ UK Cystic Fibrosis Registry. Annual Data Report 2012. Kent, Cystic Fibrosis Trust, 2013.

5 De Boeck K, Wilschanski M, Castellani C, et al. Cystic fibrosis: terminology and diagnostic algorithms. Thorax 2006; 61: 627-635.

6 Kenny SL, Shaw TD, Downey DG, et al. Eradication of Pseudomonas aeruginosa in adults with cystic fibrosis. BMJ Open Respir Res 2014; 1: e000021.

7 Kappler M, Kraxner A, Reinhardt D, et al. Diagnostic and prognostic value of serum antibodies against Pseudomonas aeruginosa in cystic fibrosis. Thorax 2006; 61: 684-688.

8 Taccetti G, Campana S, Festini F, et al. Early eradication therapy against Pseudomonas aeruginosa in cystic fibrosis patients. Eur Respir J 2005; 26: 458-461.

9 Schelstraete P, Deschaght P, Van Simaey L, et al. Genotype based evaluation of Pseudomonas aeruginosa eradication treatment success in cystic fibrosis patients. J Cyst Fibros 2010; 9: 99-103.

10 Hansen CR, Pressler T, Hoiby N. Early aggressive eradication therapy for intermittent Pseudomonas aeruginosa airway colonization in cystic fibrosis patients: 15 years experience. J Cyst Fibros 2008; 7: 523-530.

\section{Tuberculosis outbreak in East Greenland: groups at risk in an isolated arctic setting}

To the Editor:

In 2009, an unusually high number of tuberculosis (TB) cases were reported from a settlement (Settlement $\mathrm{X})$ in East Greenland. 4 years earlier, screening among schoolchildren had documented all children in this settlement to be free of Mycobacterium tuberculosis infection (MTI), whereas similar screenings had shown an MTI prevalence of $8 \%$ among schoolchildren in the rest of East Greenland [1]. The average TB incidence rate in East Greenland 5 years prior to the outbreak was 300 per 100000 populations (fig. 1) [2, 3].

The documentation of areas with differences in M. tuberculosis transmission prior to a TB outbreak provided a special opportunity to study the risk of TB in these settings that have an otherwise comparable population. The objective of the study was to estimate the risk of TB and MTI during an outbreak, and to evaluate whether individuals from a previously $M$. tuberculosis transmission-free environment exhibited particular risk.

We conducted a cohort study including all inhabitants living in East Greenland on January 1, 2008 (n=3541). Participants were followed until TB notification, death, emigration or December 31, 2012. A personal Civil Registration System (CRS) identifier given to Greenlandic citizens at birth combined data across public registries. The cohort was stratified by residency (Settlement X or the rest of East Greenland) at study entry.

Notification of TB to the National Board of Health is mandatory and the Greenlandic TB case definition follows that of the World Health Organization (WHO) $[4,5]$. A positive interferon- $\gamma$ release assay (IGRA) (QuantiFERON-TB Gold; Cellestis, Venlo, the Netherlands) defined an MTI case. IGRA results among the cohort participants were obtained from routine diagnostics, contact tracing or previously conducted population screening and projects $[1,6]$. Information on covariates was obtained from the CRS, TB notifications and medical records. A Greenlandic birthplace of both parents defined Greenlandic heritage.

Since 1955, all newborns have been offered bacille Calmette-Guérin (BCG) vaccination with national coverage rates of $90-99 \%$. However, the BCG vaccination programme was temporarily discontinued between 1991 and 1996, and children born in these years were considered unvaccinated [2, 6, 7].

Crude TB incidence rates (IR) were estimated as TB cases per 100000 person-years. Incidence rate ratios were estimated with Cox proportional hazard models with age as the underlying time axis and baseline hazard rate stratified by sex [8]. 
Age-specific MTI prevalences as of January 1, 2013, were estimated from all IGRA results since 2005 using an expectation-maximisation algorithm as a function of calendar time [9]. Time of birth or last negative test and time of first positive test defined the limits of the interval in which individuals were considered infected. Individuals with only negative results were considered right-censored at time of the last test. An MTI population prevalence was estimated by averaging the age-specific MTI prevalences with the percentages of the population in each age group. SAS statistical software, version 9.4 (SAS Institute, Cary, NC, USA) was used for analyses.

The Committee for Scientific Research in Greenland (Copenhagen, Denmark) approved the study (approval no. 2012-071304). All referred studies were individually approved by the Committee and fulfilled the Helsinki II declaration.

Table 1 presents demographic data, estimated MTI prevalence and TB IR for East Greenland. During the study period, 127 cohort participants were diagnosed with TB (fig. 1).

MTI prevalence was estimated on the basis of 4060 IGRAs (1157 positive) from 2238 cohort participants (844 positive individuals). For Settlement X, estimated MTI prevalence increased overall to 60.9\%, and among teenagers born between 1991 and 1996, to 79.1\%. For the rest of East Greenland, the numbers were $37.5 \%$ and $41.9 \%$, respectively. 62 cohort participants from Settlement X participated in the 2005 school screening where all participants were MTI negative; 44 (75\%) of these had become positive before the end of the study period. For the rest of East Greenland, the MTI prevalence among schoolchildren who participated in the 2005 screening changed from $8 \%$ to $32 \%$.

Participants were followed for 17028 person-years. The TB IR increased to 2695 per 100000 person-years in Settlement X and to 1604 per 100000 person-years for the rest of East Greenland. The TB IR was 2.48 (95\% CI 1.6-3.85) times higher in Settlement X as compared with the rest of East Greenland. Overall, teenagers had the highest TB IR in both locations, but with a pronounced difference by place of residency: 4.08 (95\% CI 2.28-7.31) times higher in Settlement X than in the rest of East Greenland.

TB IR more than doubled during the outbreak in East Greenland from 2009 to 2012. The risk of TB and MTI was especially pronounced in individuals from the previously $M$. tuberculosis transmission-free Settlement X. For these individuals, the TB IR increased more than five-fold. The highest TB IR was observed among teenagers, and teenagers from Settlement $\mathrm{X}$ experienced the highest rate. Likewise, the estimated MTI prevalence was high, especially among BCG-unvaccinated individuals born in 19911996, among whom 79\% from Settlement X and 42\% from the rest of East Greenland were estimated to have MTI.

Compared with TB IRs from other high TB burden countries [10], the TB IR in East Greenland was high and approaches rates observed in Greenland before the 1950s (2000 per 100000) [11] despite a low HIV prevalence and almost no TB drug resistance [7, 12]. While crowding, poverty and smoking are highly
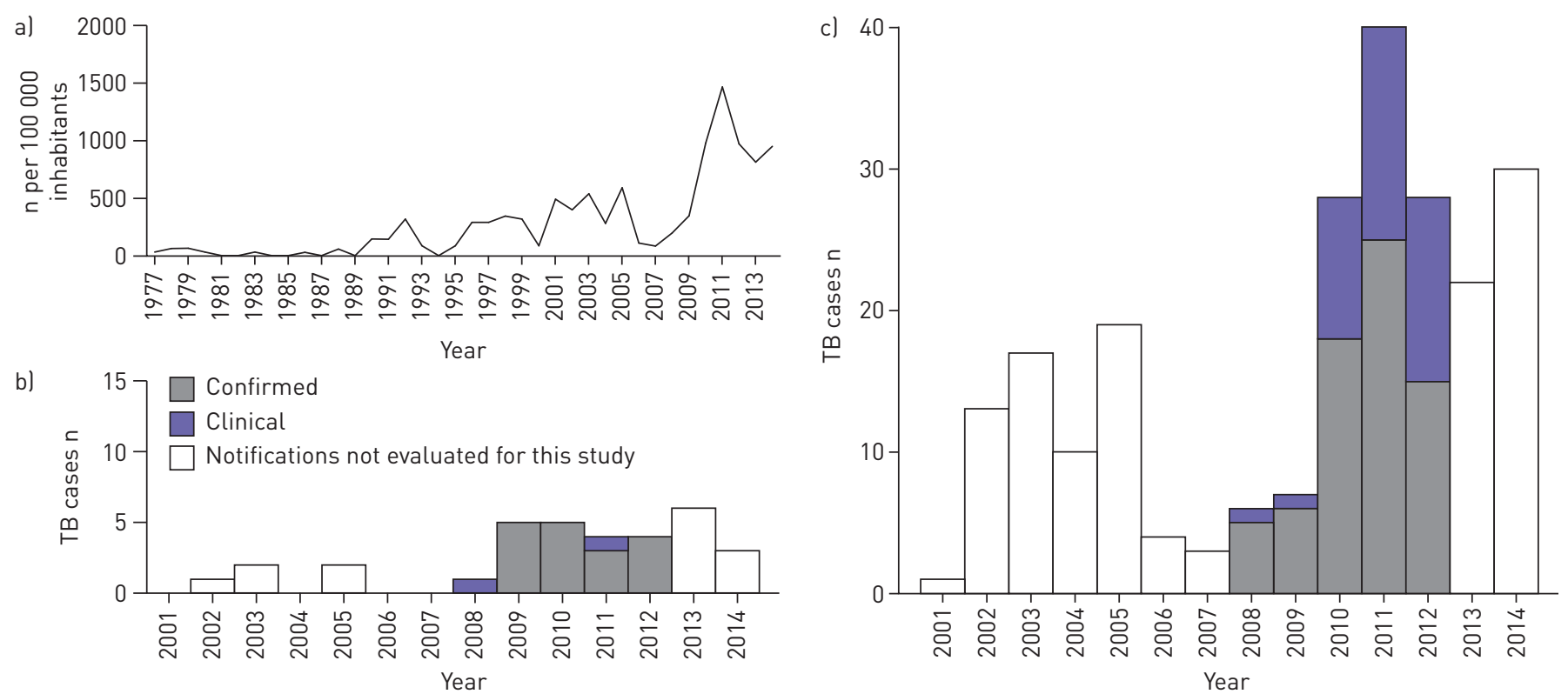

FIGURE 1 a) Tuberculosis (TB)-notified individuals from 1977 to 2014 in East Greenland per 100000 inhabitants [2, 3]. All TB cases in East Greenland from 2008 to 2012 stratified by place of residence at time of diagnosis: b) Settlement X; c) rest of East Greenland. 
TABLE 1 Demographic characteristics of the study cohort, Mycobacterium tuberculosis infection prevalence as of January 1, 2013, and tuberculosis (TB) incidence rates (IRs) per 100000 person-years, presented by residency

\begin{tabular}{|c|c|c|c|c|c|}
\hline Demographic characteristics & & Settlement $\mathrm{X}$ & & Rest of East Greenland & \\
\hline Total participants & & $356(100)$ & & $3185(100)$ & \\
\hline Greenlandic $^{\#}$ & & 345 (96.9) & & $2838(89.1)$ & \\
\hline Females & & $168(47.2)$ & & $1542(48.4)$ & \\
\hline \multicolumn{6}{|l|}{ Year of birth } \\
\hline Born after 1996 & & 80 (22.5) & & $771(24.2)$ & \\
\hline Born 1991-1996 & & $51(14.3)$ & & $357(11.2)$ & \\
\hline Born before 1991 & & 225 (63.2) & & $2057(64.6)$ & \\
\hline Age at TB diagnosis years median (IQR) & & $18(16-30)$ & & $22(18-29)$ & \\
\hline \multicolumn{6}{|l|}{ M. tuberculosis infection $\%(95 \% \mathrm{Cl})$} \\
\hline All & & $60.9(54.8-66.5)$ & & $37.5(35.2-39.7)$ & \\
\hline Born after 1996 & & $48.4(37.4-59.6)$ & & $14.3(11.5-17.6)$ & \\
\hline Born 1991-1996 & & $79.1(65.5-88.2)$ & & $41.9(36.4-47.6)$ & \\
\hline Born before 1991 & & $56.1(48.7-63.2)$ & & $48.3(45.0-51.6)$ & \\
\hline TB incidence & Cases n/person-years & IR (95\% CI) & Cases n/person-years & IR $(95 \% \mathrm{CI})$ & $\operatorname{IRR}^{\pi}(95 \% \mathrm{CI})$ \\
\hline Total & $28 / 668$ & $1730(1195-2506)$ & $99 / 15360$ & 704 (577-859) & $2.48(1.60-3.85)$ \\
\hline 2008 & $1 / 351$ & $286(40-2029)$ & $6 / 3168$ & $197(88-437)$ & $1.20(0.14-10.00)$ \\
\hline 2009 & $5 / 346$ & $1479(616-3554)$ & $7 / 3136$ & $210(94-468)$ & $7.94(2.28-27.67)$ \\
\hline 2010 & $8 / 333$ & $2463(1232-4926)$ & $21 / 3085$ & $733(47-1136)$ & $3.71(1.57-8.79)$ \\
\hline 2011 & $6 / 322$ & 1944 (873-4327) & $42 / 3013$ & 1604 (1185-2170) & $1.17(0.49-2.80)$ \\
\hline 2012 & $8 / 313$ & 2695 (1348-5388) & $23 / 2958$ & $911(605-1371)$ & $3.17(1.34-7.52)$ \\
\hline \multicolumn{6}{|l|}{ Sex } \\
\hline Females & $15 / 794$ & $1954(1178-3241)$ & $43 / 7474$ & 610 (449-828) & $2.95(1.60-5.46)$ \\
\hline Males & $13 / 873$ & 1528 (887-2632) & $56 / 7885$ & 794 (611-1032) & $2.10(1.12-3.94)$ \\
\hline \multicolumn{6}{|l|}{ Age at diagnosis years } \\
\hline $0-12$ & $0 / 380$ & & $3 / 3631$ & 90 (29-280) & $0.00(0.00)$ \\
\hline $13-19$ & $18 / 251$ & 7389 (4656-11729) & $39 / 2056$ & 2210 (1614-3024) & $4.08(2.28-7.31)$ \\
\hline$\geqslant 20$ & $10 / 1036$ & 1000 (538-1858) & $57 / 9671$ & $633(486-824)$ & $1.49(0.74-3.00)$ \\
\hline
\end{tabular}

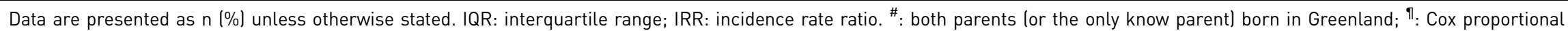
hazard model with age as the underlying time axis and baseline hazard rate stratified by sex. 
prevalent in East Greenland, living standards are improving as in the rest of Greenland [13, 14]. The discontinuation of neonatal BCG vaccinations from 1991 to 1996 accounts for some of the increased rates in teenagers as compared with other age groups [6]. However, the difference in risk related to residency is not explained by a lack of vaccination and should be further studied. Teenagers from small settlements have to move to larger towns to finish secondary school and we speculate whether this physical relocation could increase the TB risk during an outbreak because of a possibly increased infection pressure in boarding homes combined with the stress of being relocated at a young age.

No schoolchildren in Settlement X had MTI in 2005, indicating that they had been raised in a low TB endemic period with presumably no $M$. tuberculosis transmission [1]. Of these previously IGRA-negative schoolchildren, 75\% were IGRA-positive after 2010. Since the bulk of MTI occurs among the young, a further increase in IR can be expected in years to come.

Major strengths of this study are the unique CRS linkage of registers, and the availability of longitudinal data on both TB disease and MTI. A possible weakness in estimating MTI prevalence is the assumption that tests have been performed regardless of expected results, as in population-wide screenings. Including IGRA results from M. tuberculosis-exposed individuals from contact tracings could lead to overestimation. However, most individuals had more than one IGRA performed, which strengthens the estimates of interval censuring.

In conclusion, individuals from a previously M. tuberculosis transmission-free settlement carried an extra two-fold risk of MTI and TB disease during the outbreak. Teenagers had the highest TB risk, with unvaccinated teenagers from the previously $M$. tuberculosis transmission-free settlement being especially vulnerable. Greenland has a national TB programme evaluated by WHO, and treatment and access to care are free of charge [7], yet Greenland remains a high TB incidence country a long way from achieving TB elimination [15]. The study emphasises the need to rapidly confine any TB outbreak, especially in previously transmission-free environments, and underlines the importance of identifying groups at risk in order to aid future TB interventions.

0 @ERSpublications

Teenagers from a previously $M$. tuberculosis transmission-free settlement were at particular risk during a TB outbreak http://ow.ly/KALqZ

Karen Bjorn-Mortensen ${ }^{1,2,3}$, Aase B. Andersen ${ }^{4}$, Anders Koch ${ }^{1}$, Karin Ladefoged ${ }^{5}$, Troels Lillebaek ${ }^{2}$, Sascha W. Michelsen ${ }^{1}$, Thomas Rendal ${ }^{6}$, Mikael Andersson ${ }^{1}$, Jacob Simonsen ${ }^{1}$ and Bolette Soborg ${ }^{1}$

${ }^{1}$ Dept of Epidemiology Research, Statens Serum Institut, Copenhagen, Denmark. ${ }^{2}$ International Reference Laboratory of Mycobacteriology, Statens Serum Institut, Copenhagen, Denmark. ${ }^{3}$ Greenland's Center of Health Research, Nuuk, Greenland. ${ }^{4}$ Dept of Infectious Diseases, Copenhagen University Hospital and University of Southern Denmark, Odense, Denmark. ${ }^{5}$ Dept of Internal Medicine, Queen Ingrid's Hospital, Nuuk, Greenland. ${ }^{6}$ National Board of Health, Nuuk, Greenland.

Correspondence: Karen Bjorn-Mortensen, Dept of Epidemiology Research/International Reference Laboratory of Mycobacteriology, Artillerivej 5, 2300 Copenhagen, Denmark. E-mail: kabm@ssi.dk

Received: Dec 152014 | Accepted after revision: Feb 212015 | First published online: April 162015

Support statement: The Commission for Scientific Research in Greenland, Forskningspuljen and Sundhedspuljen (Greenland Self-Government) funded the study.

Conflict of interest: None declared.

Acknowledgements: The authors thank the East Greenlandic population for participation in the study, and H.C.F. Sørensen (Tasiilaq, Greenland), and former TB nurses J. Sommer and M. Weismann (Tasiilaq, Greenland) for identifying and treating TB patients, and collecting and providing data. The authors also thank the healthcare personnel in East Greenland, the Chief Medical Officer, Queen Ingrid's Health Center (Nuuk, Greenland), Queen Ingrid's Hospital and the Central Laboratory (Nuuk, Greenland) for support and access to data.

\section{References}

1 Soborg B, Koch A, Thomsen VØ, et al. Ongoing tuberculosis transmission to children in Greenland. Eur Respir J 2010; 36: 878-884.

2 National Board of Health. Årsberetninger [Yearly Reports]. http://naalakkersuisut.gl/da/Naalakkersuisut/ Departementer/Landslaegeembedet/Aarsberetninger Date last accessed July 29, 2014.

3 Naatsorsueggissaartarfik [Greenland Statistics]. Ukiumoortumik paasissutissat ebog-isut [Statistical yearbook in eBook format]. www.stat.gl Date last accessed: January 23, 2015.

4 Chief Medical Officer of Greenland. ELI vejledning. Tuberkulose. Diagnostik, behandling, kontrol og anmeldelser samt kontaktopsporing, vaccination og forebyggelse. [ELI guideance. Tuberculosis. Diagnosis, treatment, control and notification including contact tracing, vaccination and prevention]. Nuuk, Landslægeembedet, 2007.

5 World Health Organization. Definitions and reporting framework for tuberculosis - 2013 revision. http://apps. who.int/iris/bitstream/10665/79199/1/9789241505345_eng.pdf Date last accessed: January 15, 2014. Date last updated: December 2014. 
6 Michelsen SW, Soborg B, Koch A, et al. The effectiveness of BCG vaccination in preventing Mycobacterium tuberculosis infection and disease in Greenland. Thorax 2014; 69: 851-856.

7 Naalakkersuisut. National TB strategi 2012-2016 [National TB Strategy 2012-2016]. http://dk.vintage.nanoq.gl/ Service/Publikationer/Udgivelser/2011/ /media/Naalakkersuisut/Peqqinnissaq/Tuberkulose_strategi/National\% 20TB\%20strategi\%202012\%2016_final_dk_web.ashx Date last accessed: April 6, 2012.

8 Cox DR. Partial Likelihood. Biomatrika 1975; 62: 269-276.

9 Dempster AP, Laird NM, Rubin DB. Maximum likelihood from incomplete data via the EM algorithm. $J$ R Stat Soc Ser B 1977; 39: 1.

10 WHO. Global tuberculosis report 2014. www.who.int/tb/publications/global_report/en Date last accessed: April 6, 2014.

11 Stein K. Tuberkulosen i Grønland og dens bekæmpelse - et tilbageblik og et tidsbillede [Tuberculosis in Greenland and the fight against it - looking back]. Rødovre, Hafnia Tryk AS, 1994.

12 Bjorn-Mortensen K, Ladefoged K, Obel N, et al. The HIV epidemic in Greenland - a slow spreading infection among adult heterosexual Greenlanders. Int J Circumpolar Health 2013; 72: 19558.

13 Kommuneqarfik Sermersooq. Lokalsamfundsprofiler [Local society profiles]. http://sermersooq.gl/uploads/2014/ 12/Tasiilaq_DA_Final.pdf Date last accessed: April 6, 2014.

14 SliCA. Survey of Living Conditions in the Arctic. www.arcticlivingconditions.org Date last accessed: April 6, 2015.

15 D'Ambrosio L, Dara M, Tadolini M, et al. Tuberculosis elimination: theory and practice in Europe. Eur Respir J 2014; 43: 1410-1420.

\section{Universal health coverage and social support in Senegal: a comprehensive approach against tuberculosis}

To the Editor:

The World Health Organization (WHO) recently launched the "End TB Strategy" [1] and, in collaboration with the European Respiratory Society, launched the framework for tuberculosis (TB) elimination in low-incidence countries [2]. Both documents focus on ending the global TB epidemic by 2035, through stimulating collaborative actions at country level and increased cooperation between high and low TB-incidence countries [3-5]. The world is a global village, where the increasing cross-border and cross-continental movement of people enables infectious diseases like TB to spread across communities and countries $[6,7]$. No nation is immune to the threat of infectious outbreaks $[8,9]$, and a significant reduction of TB burden in low-incidence countries will not be possible unless TB care and prevention is also consistently scaled-up in high TB-incidence countries [5]. This interdependency calls for joint collaborative actions involving governments, governmental and nongovernmental agencies, civil society, and communities, families and individuals.

Here we report the experience of StopTB Italia Onlus in collaboration with Yungar per la Pace Onlus and the Senegal National TB Control Programme in fighting TB in Senegal, a country with 19000 new TB cases and 29000 prevalent cases estimated for 2013 [10].

This 3-year project (2013-2015), founded by Fondazione Italo Monzino (Milan, Italy), uses a systemic approach to address the broad spectrum of clinical and social issues as well as structural health system limitations (infrastructure, human resources and organisation) fuelling TB in the health district of Dioffior (Senegal). The Dioffior health district is located in the southern part of the Fatick Region, and has an area of $612 \mathrm{~km}^{2}$ and a population of 80599 inhabitants (population density: 131 inhabitants per $\mathrm{km}^{2}$ ).

The project is comprehensive and includes clinical and technological support for the health service, training of health staff (involved in TB diagnosis, treatment and control) and 50 women in the villages (badieu'ngox), economic support for the patients and education of the population (table 1) [1-4]. Due to poverty in Senegal [11], the economic support provided to the patients doesn't impact on socioeconomic status, but it is sufficient to encourage patients to adhere to treatment. 20000 FCFA (Franc of the French Community of Africa) is offered to all patients who complete treatment (20000 FCFA $\approx 30 €)$. Economic benefits of 4000 FCFA $(\sim 6 €)$ are offered to the badieu'ngox for communication activities, and additional 20000 FCFA offered to those who follow the patient until the end of their treatment. Moreover, the 